\title{
UNDERSTANDING PHYTOCHEMICAL ROLES ON $\alpha$-GLUCOSIDASE INHIBITORY ACTIVITY BASED ON METABOLOMIC APPROACH OF Premna serratifolia LEAVES FROM WEST BORNEO, INDONESIA
}

\author{
D. Hadiarti ${ }^{1,2}$, W. Haryadi ${ }^{2}$, , S. Matsjeh ${ }^{2}$ and R. T. Swasono ${ }^{2}$ \\ ${ }^{1}$ Department of Chemistry Education, Muhammadiyah University of Pontianak, \\ West Borneo-78123, Indonesia \\ ${ }^{2}$ Department of Chemistry, Gadjah Mada University, Daerah Istimewa Yogyakarta-55281, \\ Indonesia \\ Corresponding Author: wnrt_haryadi@ugm.ac.id
}

\begin{abstract}
Extract of Premna serratifolia (Buas-buas) leaves has been proven as inhibitor $\alpha$-glucosidase but phytochemicals that have the biggest contribution to its bioactivity are not known. This research was designed to investigate the role of total flavonoid content (TFC), total phenolic content (TPC), total steroid content (TSC), and functional groups on the $\alpha$-glucosidase inhibitory activity of $P$. serratifolia leave extracts. Dried leaves were macerated by ethanol to obtain crude extract then partitioned by utilizing hexane, ethyl acetate, and water. Inhibited $\alpha$-glucosidase of extracts were evaluated using the PNPG method followed by determined phytochemical and analyzed functional groups using FTIR. Principal component analysis (PCA) indicated that ethyl acetate fraction was the highest correlation with acarbose equivalent. TFC and $\mathrm{H}-\mathrm{C}=\mathrm{O}$ aldehydes group were positive correlation on $\alpha$-glucosidase inhibitory activity analyzed by partial least square (PLS). The metabolomic approach can predict a significant contribution in inhibiting $\alpha$ glucosidase from different extracts of $P$. serratifolia which are flavonoid and $\mathrm{H}-\mathrm{C}=\mathrm{O}$ aldehydes group.
\end{abstract}

Keywords: $\alpha$-glucosidase, Phytochemicals, Functional Groups, P. serratifolia

RASĀYAN J. Chem., Vol. 14, No.2, 2021

\section{INTRODUCTION}

Diabetes mellitus (DM) is a chronic metabolic disorder where there is a raised level of blood glucose in the long-term resulting in insufficiency to produce insulin or inability to respond to insulin. According to The International Diabetes Federation report published in 2019, around 4.2 million deaths worldwide were caused by DM and its complications. ${ }^{1} \mathrm{DM}$ pharmacotherapy using $\alpha$-glucosidase inhibitor reduced the hydrolyzes of carbohydrate ${ }^{2}$ causing side effects such as flatulence, diarrhea, and hepatitis. ${ }^{3}$ Therefore, it is necessary to find the relative safety of the new $\alpha$-glucosidase inhibitor based on plant.

Premna serratifolia, locally known in West Borneo as Buas-buas or Ulam Singkil, belongs to the Premna genus comprised of more than 200 species spreading in Asia, Africa, and Pacific islands ${ }^{4}$. P. serratifolia leaves have been traditionally utilized to reduce blood pressure, eliminate body odor, and increase the production of breast milk ${ }^{5}$. As reported in the previous research, $P$. serratifolia leaves have biological activities such as antifungal ${ }^{6}$, larvicidal of Aedes aegypti ${ }^{7}$, hepatoprotective ${ }^{8}$, antioxidant ${ }^{9}$, and inhibitor $\alpha-$ glucosidase. ${ }^{10,11}$

The result from phytochemical screening identified flavonoids, phenolics, saponins, steroids, and tannins in extract ethanol of $P$. serratifolia which were proved to inhibit $\alpha$-glucosidase. ${ }^{10}$ Besides, LC-MS analysis of percolation and decoction extracts detected a phenolic compound which was caffeic acid that could be an $\alpha$-glucosidase inhibitor. ${ }^{11}$ Based on a previous study, there were 103 flavonoid compounds inhibiting glucosidase which is more than quinone (8), steroids (8), and phenolics (37). ${ }^{12}$ In other words, the study of secondary metabolites in $P$. serratifolia leaves extract as $\alpha$-glucosidase has not been completed because there is a possibility that other phytochemical metabolites can inhibit $\alpha$-glucosidase besides phenolics. Therefore, our research aimed to explore the secondary metabolites and functional groups influencing $\alpha$ glucosidase inhibitory activity by approaching metabolomics.

Rasayan J. Chem., 14(2), 1216-1222(2021)

http://dx.doi.org/10.31788/RJC.2021.1426320 
RASĀYAN J. Chem.

Vol. 14 | No. 2 |1216-1222 | April - June | 2021

\title{
Material
}

\section{EXPERIMENTAL}

Ethanol, hexane, ethyl acetate, quercetin, garlic acid, cholesterin, and $\mathrm{KBr}$ were purchased from Merck (Darmstadt, Germany). Other materials including $\alpha$-glucosidase, bovine serum albumin (BSA), $\rho$ nitrophenyl- $\alpha$-D-glucopyranoside (PNPG) were supplied from Sigma Aldrich (St. Louis, USA). Water was distilled obtaining from CV. General Labora (Yogyakarta, Indonesia).

\section{Plant Material}

Immatured leaves of the plant were collected in August 2020 in peatlands nearby Kapuas river, Pontianak, West Borneo. Taxonomically plant species were confirmed by botanists at the Biology Research Center of The Indonesian Institute of Sciences (LIPI). The result was established as P. serratifolia with specimen's voucher number 857/IPH.1.01/If.07/VIII/2020.

\section{Extraction and Fraction ${ }^{13,14}$}

The collected plants $(15000 \mathrm{~g})$ were cleaned and placed at room temperature to air-drying for 7 days. The dried leaves grounded to powder and macerated on 3 days in ethanol substituted every sequent day. The liquid extract was filtered and evaporated under the reduced pressure for $80 \mathrm{~min}$ at $40{ }^{\circ} \mathrm{C}$. Partitioned by liquid-liquid partition using different polarities of solvent, the ethanol extract was diluted gradually with hexane, ethyl acetate, and water. Finally, all of the extracts were filtered, evaporated, and reserved at $-4^{\circ} \mathrm{C}$ for subsequent analysis.

\begin{abstract}
Alpha-glucosidase Inhibitory Assay ${ }^{15,16}$
The chromogenic PNPG method was utilized to assay the inhibition of $\alpha$-glucosidase. Known as an inhibitor of the $\alpha$-glucosidase enzyme, acarbose was represented as a positive control, and PNPG has reflected substrate. A total of $10 \mu \mathrm{L}$ of $30 \mathrm{mg} / \mathrm{mL}$ P. serratifolia extract and $50 \mu \mathrm{L}$ phosphate buffer was added with $25 \mu \mathrm{L} \alpha$-glucosidase in phosphate buffer ( $\mathrm{pH} 7$ ) and $25 \mu \mathrm{L}$ PNPG. For preparing the blank, the extract solution was added in all reaction reagent devoid enzyme solution, then it was incubated at $37{ }^{\circ} \mathrm{C}$ for 30 min. Before the absorbance was read by spectrophotometer at $400 \mathrm{~nm}, 15 \mu \mathrm{L}$ sodium carbonate $0.2 \mathrm{M}$ was appended to stop the reaction. The activity of $\alpha$-glucosidase inhibition was expressed as acarbose equivalent (mmol ACE/100 g extract).
\end{abstract}

\section{Determination of Total Flavonoids ${ }^{17}$}

Measured by $\mathrm{AlCl}_{3}$ method, quercetin was established as the standard for determining TFC. The absorbance of quercetin in extracts was confirmed at $725 \mathrm{~nm}$ using a UV-Vis spectrophotometer (Shimazu 2450, Tokyo, Japan). Quercetin was used to express mg quercetin equivalent (QE) per $100 \mathrm{~g}$ extract.

\section{Total Phenolics Determination ${ }^{17,18}$}

The total phenolics content was determined by the existing Folin-Ciocalteu method preparing gallic acid as the standard. Observed by a Shimadzu $2450 \mathrm{UV}$-Vis spectrophotometer (Tokyo, Japan), the absorbance of the gallic acid solution was detected at $752 \mathrm{~nm}$. TPC was expressed as gallic acid equivalent (GAE) in 100 g P. serratifolia extract.

\section{Calculation of Total Steroid ${ }^{19,20}$}

Applying cholesterin as a standard, the assay of TSC was performed by the Liebermann-Burchard method. The cholesterin solution was scanned within a wavelength of $420 \mathrm{~nm}$ utilizing a UV-Vis spectrophotometer (Tokyo, Japan). Cholesterin equivalent (CE) in $100 \mathrm{~g}$ extracts was utilized to express the results.

\section{Identification of Functional Groups using FTIR}

The FTIR spectra were measured from extracts by utilizing Shimadzu IRPrestige-21 (Tokyo, Japan) accoutered with a detector of DLATGS. Each $2 \mathrm{mg}$ of $P$. serratiolia extract was mixed homogeneously by $180 \mathrm{mg}$ of $\mathrm{KBr}$ formed with a pressure of 8 tons for $15 \mathrm{~min}$. All extracts were investigated in the wavenumber of $4000-400 \mathrm{~cm}^{-1}$ with a resolution of $4 \mathrm{~cm}^{-1}$. Controlled by Shimadzu IRSolution 1.60 software (Tokyo, Japan), FTIR spectrums were obtained in 45 scans/min with three measurements for each extract. 


\section{Statistical Analysis ${ }^{21,22}$}

The analysis of variance and Turkey test $(\mathrm{p}<0.05)$ were utilized to evaluate data that indicated the differences among the extract yield, TFC, TPC, TSC, and $\alpha$-glucosidase inhibitory activity. To further statistical analysis of multivariate, PCA and PLS were conducted using XLSAT 5.03 software Addinsoft (New York, America). PCA was utilized to observe phytochemical and $\alpha$-glucosidase activity on solvent of extract. The correlation between phytochemical and functional groups from FTIR spectra on $\alpha$ glucosidase activity was determined by utilizing PLS.

\section{RESULTS AND DISCUSSION}

\section{Extraction Yield, Phytochemical, and Alpha-glucosidase Inhibitory Activity}

$P$. seraatifolia leaves were extracted using ethanol and were fractionated by utilizing different polarities of solvent. In Table-1, the yield increased in the following order: water>ethanol>ethyl acetate $>$ and hexane. It is worth mentioning that the higher polarity of solvent used the more yield produced. According to the result of extraction, $P$. serratifolia contained more polar compounds than semi or non-polar phytochemicals.

The determination of TFC in Table-1 revealed that flavonoids increased in the order of water $>$ hexane $>$ ethyl acetate $>$ ethanol. The analysis of TPC demonstrated that phenolic compounds enhancement as the polarity of solvent increased. The phenolic levels in the following order from the highest to the lowest were water $>$ ethanol $>$ ethyl acetate $>$ hexane. Different from the result in determining TPC, the concentration of steroid was reduced with an accrue in the dielectric constant of the solvent.

Tabel-1: Extraction Yield, a Total of Phytochemical Content, and $\alpha$-glucosidase inhibitory of $P$. serratifolia Extracts

\begin{tabular}{c|c|c|c|c|c}
\hline Solvent & $\begin{array}{c}\text { Fraction } \\
\text { Yields } \\
(\%)\end{array}$ & $\begin{array}{c}\text { Total Flavonoid } \\
\text { Content } \\
\text { (g QE/100 g } \\
\text { extract) }\end{array}$ & $\begin{array}{c}\text { Total Phenolic } \\
\text { Content } \\
\text { (g GAE/100 g } \\
\text { extract) }\end{array}$ & $\begin{array}{c}\text { Total Steroid } \\
\text { Content } \\
\text { (g CE/100 g } \\
\text { extract) }\end{array}$ & $\begin{array}{c}\text { a-glucosidase } \\
\text { (mg ACAE/ 100 } \\
\text { g extract) }\end{array}$ \\
\hline Ethanol & 16.44 & $2.36 \pm 0.92^{\mathrm{a}}$ & $10.82 \pm 0.62^{\mathrm{a}}$ & $0.81 \pm 0.02^{\mathrm{a}}$ & $55.89 \pm 0.08^{\mathrm{a}}$ \\
\hline Hexane & 7.74 & $6.34 \pm 0.90^{\mathrm{b}}$ & $5.99 \pm 0.12^{\mathrm{b}}$ & $1.70 \pm 0.15^{\mathrm{b}}$ & $39.74 \pm 0.61^{\mathrm{b}}$ \\
\hline Ethyl acetate & 10.21 & $6.11 \pm 0.72^{\mathrm{c}}$ & $6.66 \pm 0.16^{\mathrm{c}}$ & $1.49 \pm 0.26^{\mathrm{c}}$ & $77.63 \pm 0.18^{\mathrm{c}}$ \\
\hline Water & 30.63 & $6.56 \pm 0.15^{\mathrm{d}}$ & $21.84 \pm 0.07^{\mathrm{c}}$ & $0.89 \pm 0.12^{\mathrm{c}}$ & $\mathrm{na}$ \\
\hline
\end{tabular}

Values expressed are means \pm standard deviation of three repetitions. GAE: Gallic acid equivalent; QE: Quercetin equivalent; CE: Cholesterin equivalent; ACAE: Acarbose equivalent. The significant differences among extracts were indicated by superscript letters (a-d) on every column $(\mathrm{p}<0.05)$. na: not active.

Data conferred in Table-1, indicate that the ethyl acetate fraction of $P$. serratifolia leaves was the most potent $\alpha$-glucosidase inhibitor which compared ethanol extract and hexane fraction. It was obvious that the semi-polar solvent had the most ability to inhibit $\alpha$-glucosidase. Similarly, to our results, Lotulung et al., Yuliet et al., and Zhao et al. ${ }^{23-25}$ revealed that ethyl acetate fraction exhibited more effective $\alpha$-glucosidase inhibitory activity than ethanol, water, and hexane. Therefore, the possibility of $\alpha$-glucosidase inhibitory activity is strongly influenced by the semi-polar of flavonoids, phenolics, and steroids.

\section{Roles of Phytochemical on Alpha-glucosidase Inhibitory Activity}

The PCA was operated to investigate the correlation between TFC, TPC, TSC, and $\alpha$-glucosidase inhibition from extracts (Fig-1). The PCA evaluation exhibited a PC of 98,30\%. The biplot shows that $\alpha$-glucosidase and ethyl acetate fraction were located at the same positive area. On the other hand, the ethyl acetate fraction of $P$. serratifolia indicated the greatest correlation of $\alpha$-glucosidase activity.

The secondary metabolites were combined to $\alpha$-glucosidase inhibitory activity by utilizing multivariate data analysis whereby a PLS. The bioactivity was used as the response variable (y), while TPC, TFC, and TSC were deputized as the estimating variable (x). The result demonstrates that TFC had the highest standardization coefficient (Fig.-2).

According to the result, it indicates that TFC was the greatest contributor to $\alpha$-glucosidase inhibitory activity. Related to the previous review literature, flavonoids affected $\alpha$-glucosidase inhibitory activity more than steroid and phenolic compounds. ${ }^{12}$ Flavonoids are potential inhibitors of $\alpha$-glucosidase because they 
function as hypoglycemic and antihyperglycemic. ${ }^{26,27}$ The investigation of molecular docking analysis results shows that the complexes of flavonoid with $\alpha$-glucosidase were maintained by hydrogen bonding and hydrophobic interactions. ${ }^{28}$

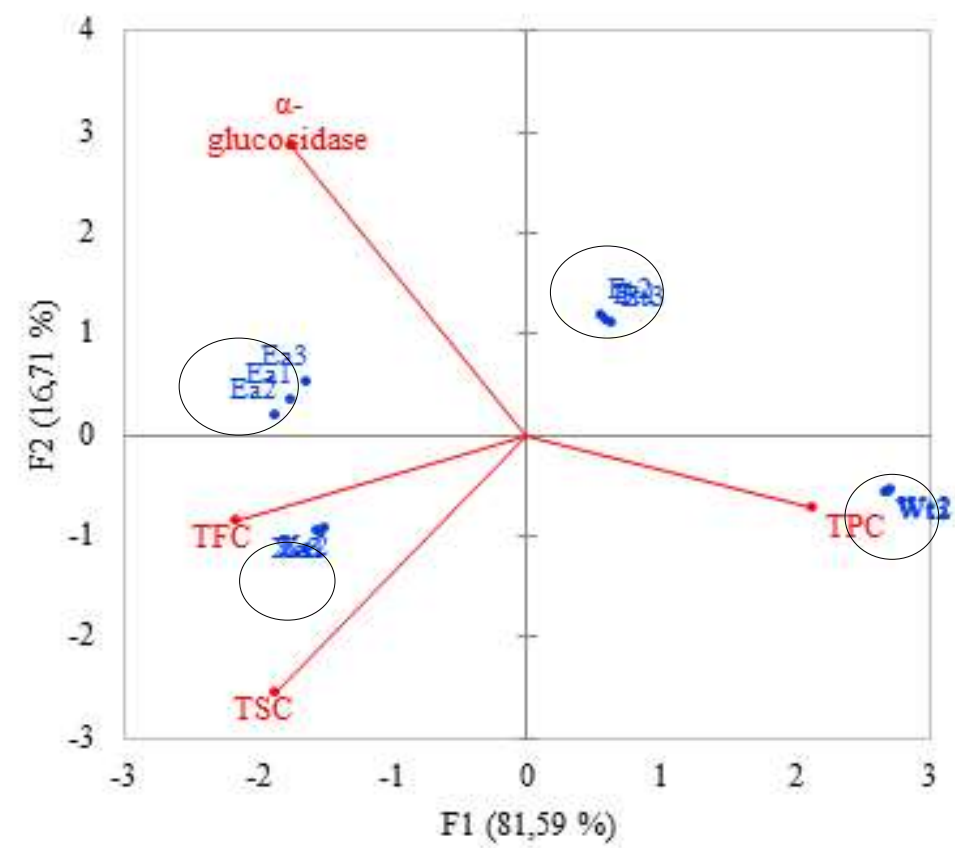

Fig.-1: PCA Plot of TFC, TPC, TSC, and $\alpha$-glucosidase of $P$. serratifolia Leaves Extracts

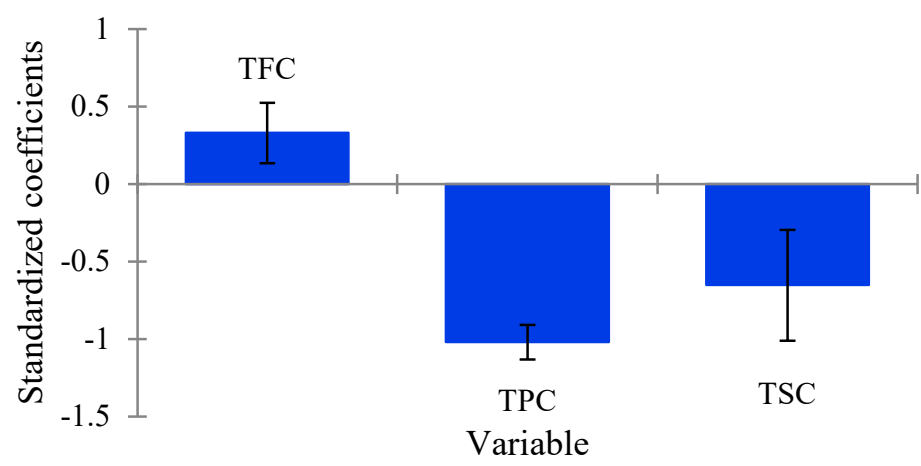

Fig.-2: Standardization Coefficient Plot of Phytochemical and $\alpha$-glucosidase of $P$. serratifolia Leaves Extracts

\section{Correlation of Functional Groups to Extract and Alpha-glucosidase Inhibitory Activity}

The FTIR spectra (Fig-3) were generated in the mid-infrared region (4000-400 $\left.\mathrm{cm}^{-1}\right)$ to select a functional group from the chemical in P. serratifolia extracts. Water fraction denoted a lower peak absorption intensity compared to other extracts. However, ethanol, hexane, and ethyl acetate represented a similar spectral pattern qualitatively albeit with different values of absorption intensity. Therefore, it was assumed the similar composition of the metabolite in ethanol, hexane, and ethyl acetate while the diverse level of concentration. There is a difference in the intensity of the absorbance value at a wavenumber of 1320-1000 $\mathrm{cm}-1$ with the highest value found in ethanol extract. Within the range of $1680-1640 \mathrm{~cm}^{-1}$, the ethanol extract and ethyl acetate fraction have a higher value than hexane fraction.

The PCA was applied to the FTIR spectra to evaluate the possible differences or similarities of the functional group which has a major contribution to the level of $\alpha$-glucosidase activity among different $P$. 
RASĀYAN J. Chem.

Vol. 14 | No. 2 |1216-1222| April - June | 2021

serratifolia extracts. PCA evaluation showed a PC of $88.72 \%$ that the biplot could organize samples based on solvents, functional groups, and $\alpha$-glucosidase activity. The PCA score plot reflected that the water fraction was separate from other extracts. In Fig.-4, the ethanol, ethyl acetate, and hexane were adjacent in their position in PCA plot. This closeness shows that the composition and level of metabolite extracted with those solvents were almost similar.

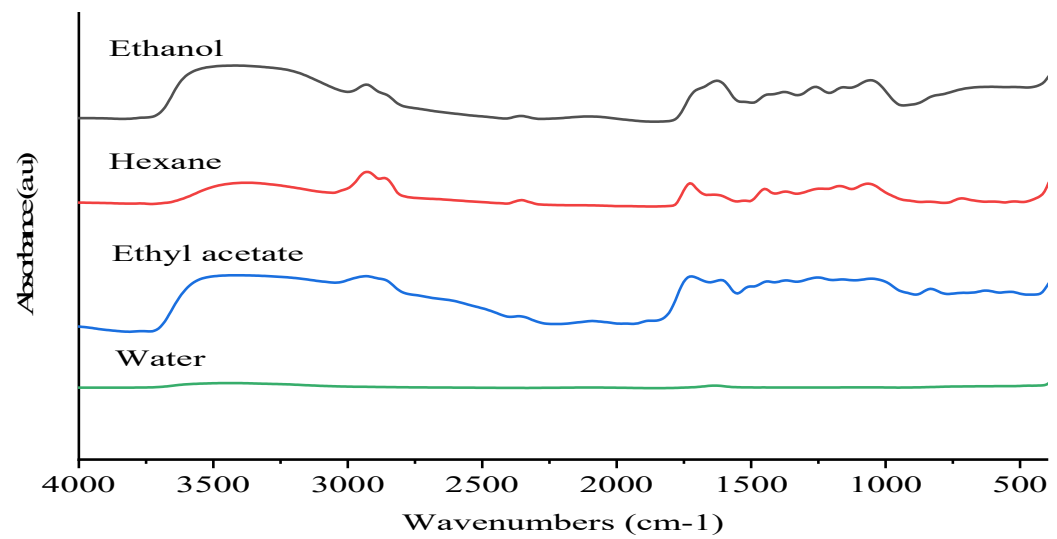

Fig.-3: FTIR Spectrum of $P$. serratifolia Leaves Extracts

Tabel-2: Functional Groups present of FTIR-data in P. serratifolia Leaves Extracts

\begin{tabular}{c|c}
\hline Assign functional group & Wavenumber $\left(\mathrm{cm}^{-1}\right)$ \\
\hline O-H & $3500-3200$ \\
\hline $\mathrm{C}-\mathrm{H}$ alkanes & $3000-2850$ \\
\hline $\mathrm{H}-\mathrm{C}=\mathrm{O}$ aldehydes & $2830-2695$ \\
\hline $\mathrm{C}=\mathrm{O}$ carbonyls & $1760-1665$ \\
\hline $\mathrm{C}=\mathrm{O}$ aldehydes & $1740-1720$ \\
\hline $\mathrm{C}-\mathrm{H}$ sp2 & $1470-1450$ \\
\hline $\mathrm{C}-\mathrm{H}$ sp3 & $1370-1350$ \\
\hline $\mathrm{C}=\mathrm{C}$ alkenes & $1680-1640$ \\
\hline $\mathrm{C}-\mathrm{O}$ & $1320-1000$
\end{tabular}

The identification of functional groups in P. serratifolia extracts was then coupled to $\alpha$-glucosidase inhibitory activity by using a fingerprint metabolomic approach with a PLS regression method. The estimating variable $(\mathrm{x})$ represented the absorbance of the functional groups, while the response matrix (y) reflected $\alpha$-glucosidase inhibition. Figure- 4 presents that $\mathrm{H}-\mathrm{C}=\mathrm{O}$ aldehydes had the highest standardization coefficient which suggests the greatest contributor for inhibiting $\alpha$-glucosidase. $\mathrm{C}-\mathrm{H}$ alkanes have a negative regression which indicates a negative correlation with $\alpha$-glucosidase activity.

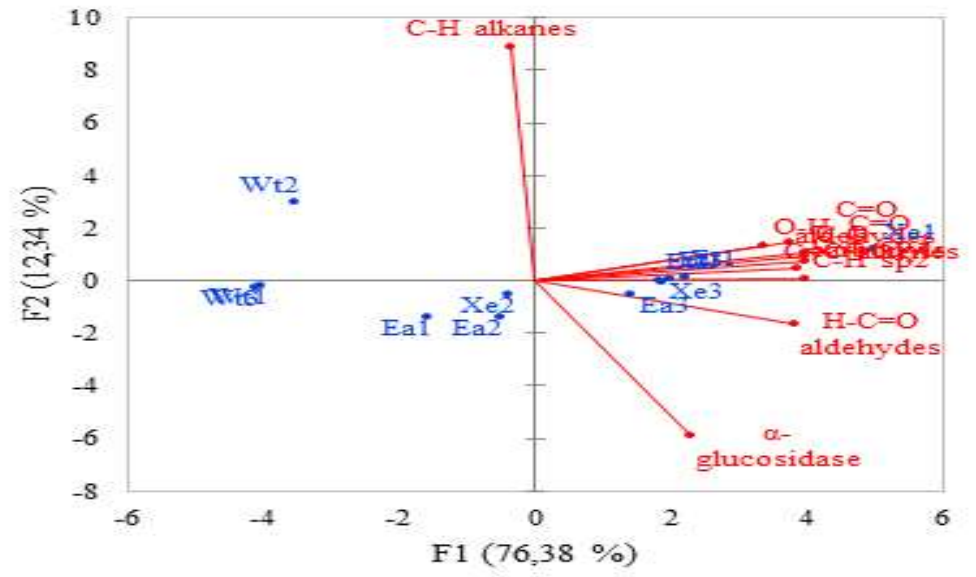

Fig.-4: Geographical-origin-based PCA Score Plot of FTIR-data of P serratifolia Leaves Extracts on Pareto Scaling $\left(4000-400 \mathrm{~cm}^{-1}\right)$ 


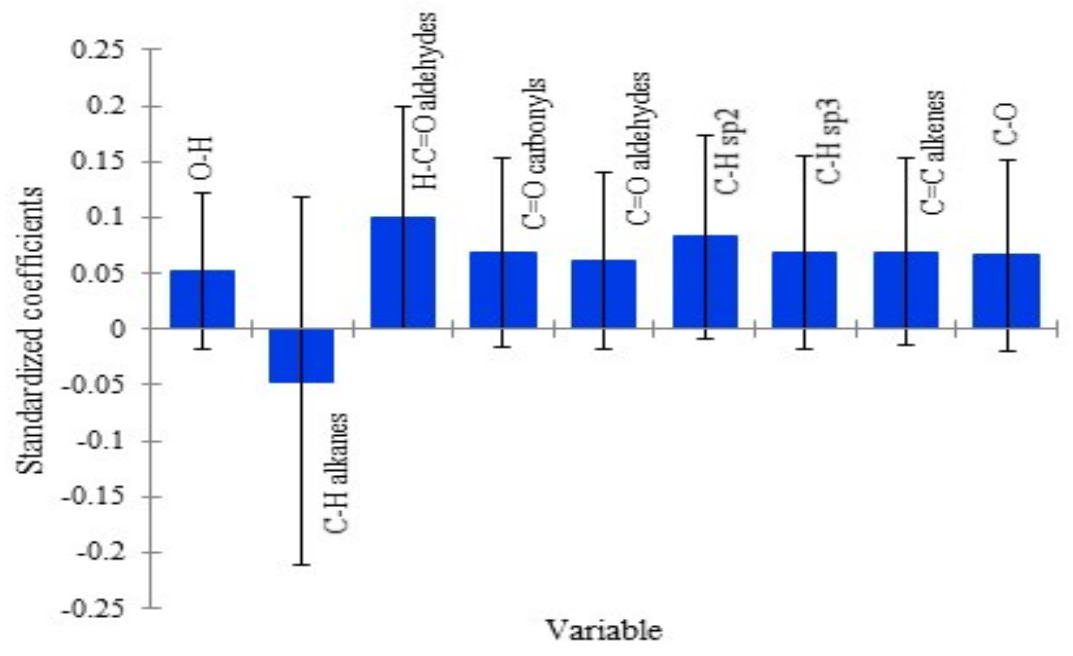

Fig.-5: Standardization Coefficient Plot of Functional Groups and alpha-glucosidase inhibitory activity of $P$. serratifolia Leaves Extracts.

\section{CONCLUSION}

Among the different extracts tested, the most potential $\alpha$-glucosidase inhibitor was found in the ethyl acetate fraction. The total flavonoid content (TFC) in P. serratifolia extract can be related to the higher observed $\alpha$-glucosidase inhibition of ethyl acetate fraction. FTIR-based metabolomics approach that $\quad \mathrm{H}-\mathrm{C}=\mathrm{O}$ aldehydes positively was correlated to inhibit $\alpha$-glucosidase activity, while $\mathrm{C}-\mathrm{H}$ alkanes revealed a negative correlation.

\section{ACKNOWLEDGEMENT}

Gratefulness to the Endowment Fund for Education (LPDP) of The Ministry of Finance Indonesia (Kemenkeu) that had been funded the research and scholarship. Thankful also to the chemistry laboratory staff of Muhammadiyah University of Pontianak who helped to collect fresh leaves of P. serratifolia.

\section{REFERENCES}

1. International Diabetes Federation, IDF Diabetes Atlas, 9th edn, International Diabetes Federation, Brussels, Belgium, (2019), Available at: https://www.diabetesatlas.org

2. S. E. Izucchin, R.M. Bergenstal, J. B. Buse, M. Diamant, E. Ferrannini, M. Nauck, A. L. Peters, A. Tsapas, R. Wender, and D. R. Matthews, Diabetes Care, 38, 140(2015), DOI:10.2337/dc14-2441

3. S. Rouzbehan, S. Moein, A. Homaei, and M. R. Moein, Pharmaceutical Biology, 55, 1483(2017), DOI: $10.1080 / 13880209.2017 .1306569$

4. R. Dianita, and I. Jantan, Pharmaceutical Biology, 55, 1715(2017), DOI:10.1080/13880209.2017.1323225

5. S. Hasanah, M. A. Wibowo, and N. Idiawati, Jurnal Kimia Khatulistiwa, 4, 101(2015).

6. S. Wahyuni, Mukarlina, and A. H. Yanti, Protobiont, 3, 274(2014), DOI: $10.26418 /$ protobiont.v3i2.6835

7. M. A. Lestari and A. H. Yanti, Protobiont, 3, 247(2014), DOI:10.26418/protobiont.v3i2.6831

8. R. Vadivu, A. J. Suresh, K. Girinath, P. B. Kannan, R. Vimala, and N. M. S. Kumar, Journal of Scientific Research, 1, 145(2009), DOI:10.3329/jsr.v1i1.1046

9. Isnindar, W. Subagus, S. Widyarini, and Yuswanto, Traditional Medicine Journal, 21, 111(2016), DOI: $10.22146 /$ tradmedj. 1729

10. D. Hadiarti, Traditional Medicine Journal, 22, 80(2017), DOI: 10.22146/tradmedj.27917

11. K. H. Timotius, A. Simamora, and A. W. Santoso, Pharmacognosy Journal, 10, 1114(2018), DOI:10.5530/pj.2018.6.189

12. Z. Yin, W. Zhang, F. Feng, Y. Zhang, and W. Kang, Food Science and Human Wellness, 3, 136(2014), 
RASĀYAN J. Chem.

Vol. 14 | No. 2 |1216-1222 | April - June | 2021

DOI: $10.1016 /$ j.fshw.2014.11.003

13. Yuliet, E. Y. Sukandar, K. Budipramana, and I. K. Adnyana, Rasayan Journal of Chemistry. 13, 826(2020), DOI:10.31788/RJC.2020.1325607

14. A. Malik, L. Marpaung, M. P. Nasution, \& P. Simanjuntak, Rasayan Journal of Chemistry. 12, 1175(2019), DOI: 10.31788/RJC.2019.1235082

15. A. Mollica, G. Zengin, M. Locatelli, A. Stefanucci, A. Mocan, G. Macedonio, S. Carradori, O. Onaolapo, A. Onaolapo, J. Adegoke, M. Olaniyan, A. Aktumsek, and E. Novellino, Journal of Functional Foods, 35, 32(2017), DOI:10.1016/j.jff.2017.05.001

16. S. Murugesu, Z. Ibrahim, Q. U. Ahmed, N.I.N Yusoff, B. F. Uzir, V. Perumal, F. Abas, K. Saari, H. El-Seedi, and A. Khatib, Molecules, 23, 1(2018), DOI:10.3390/molecules23092402

17. S. Uysal, G. Zengin, M. Locatelli, M. B. Bahadori, A. Mocan, G. Bellagamba, E. D. Luca, A. Mollica, and A. Aktumsek, Frontiers in Pharmacology, 8, 1(2017), DOI:10.3389/fphar.2017.00290

18. S. Shiyan, Fitrya, Arimia and G. Pratiwi, Rasayan Journal of Chemistry. 13, 1472(2020), DOI:10.31788/RJC.2020.1335755

19. J. K. Adu, C. D.K. Amengor, N. Kabiri, E. Orman, S. A. G. Patamia, and B. K. Okrah, International Journal of Food Science, 2019, 1(2019), DOI:10.1155/2019/9045938

20. A. Palshetkar, N. Pathare, N. Jadhav, M. Pawar, A., S. Kulkarni, and K. K. Singh, BMC Complementary Medicine and Therapies, 20, 69(2020), DOI:10.1186/s12906-020-2816-X

21. E. Rohaeti, F. Karunina, and M. Rafi, Indonesian Journal of Chemistry. 21, 128(2020), DOI:10.22146/ijc.54577

22. M. F. Kurniawan, N. Andarwulan, N. Wulandari, and M. Rafi, Food Science and Biotechnology, 26, 1475(2017), DOI:10.1007/s10068-017-0228-6

23. Yuliet, E. Y. Sukandar, and I. K. Adnyana, Indonesian Journal of Pharmaceutical Science and Technology, 1, 25(2018), DOI:10.24198/ijpst.v1i1.16120

24. P. D. N. Lotulung, T. Mozef, C. Risdian, and A. Darmawan, Indonesian Journal of Chemistry, 14, 7(2014), DOI:10.22146/ijc.21261

25. C. Zhao, J. Chen, J. Shao, J. Shen, X. Xu, K. Li, W. Gu, M. Zhao, and J. Fan, Holzforschung, 72 , 1017(2018), DOI:10.1515/hf-2018-0081

26. J. Chen, Y. Wu, J. Zou, and K. Gao, Bioorganic \& Medicinal Chemistry, 24, 1488(2016), DOI:10.1016/j.bmc.2016.02.018

27. B. W. Zhang, X. Li, W. L. Sun, Y. Xing, Z. L. Xiu, C. L. Zhuang, and Y. S. Dong, Journal of Agricultural and Food Chemistry, 65, 8319(2017), DOI:10.1021/acs.jafc.7b02531

28. C. He, X. Liu, Z. Jiang, S. Geng, H. Ma, and B. Liu, Foods, 8, 1(2019), DOI:10.3390/foods8090355

[RJC-6320/2020] 